\title{
RETHINKING THE REFLECTIVE PRAXIS OF THE NAME SOCIAL SCIENCE: PEDAGOGICAL 'MISCHIEF' IN THE GRADE 4 TO 9 SOCIAL SCIENCE CURRICULUM
}

\author{
DOI: http://dx.doi.org/10.17159/2223-0386/2017/n18a5 \\ Maserole Christina Kgari-Masondo \\ History Education, Edgewood \\ University of KwaZulu Natal \\ Chrismasondo@gmail.com or Kgarimasondo@ukzn.ac.za
}

\section{Abstract}

The article depicts the global history of the Social Science (SS) curriculum to illustrate that already by the $19^{\text {th }}$ century Geography and History had been divided. The influence of non-integration of the SS was mainly by Geographical determinism which promulgated that the natural environment prescribes how people live, suggesting that all people living in a specific natural environment would respond in the same way when engaging with their environment. Such thinking inferred that human agency and culture had no role in such interaction. As a result some historians have neglected the environment in the study of History, which in turn served to further set boundaries for integration in SS. South Africa also subscribed to such a division as policy makers stipulated categorically in the Curriculum Assessment Policy Statement (CAPS) of Grade 4 to 9 that, SS is integrative in nature but has to be taught and administered as distinct Geography and History components. Integration occurs administratively when exam marks have to be combined as one to comprise SS - which is mischievous as it does not depict the reflective praxis of the subject pedagogically. The teaching and learning in terms of the content is divided into Geography and History but the summative is the only indicator of an integrated subject. From literature surveyed no investigation on the set topic has been undertaken in SA. The article thus proposes that non-integration of SS pedagogically speaking is 'mischievous' in the teaching and learning of SS in schools because the name negates what occurs practically in the teaching of the subject. The article through qualitative research drawing from interviews of trainee teachers enrolled in the Post Graduate Certificate Education doing SS at the University of KwaZulu-Natal enlightens the 'mischiefs' embedded in the SS curriculum. Drawing from some of the trainee teachers' views the conclusions and recommendations of the article are that, SS has to be integrated because as is it is pedagogically misleading and compromises the quality of teaching in the learning area. This implies that, SS is an integrated subject and has to be taught as such because Geography cannot be taught without History or vice versa, because the one without the other equates with an incomplete learning area. 
Keywords: Integration; Pedagogy; Geography; History; Social Studies; Mischief.

\section{Introduction}

South Africa (SA) as in many parts of the world has made great strides in transforming History and Geography curricula as independent subjects within the SS learning area. CAPS for SS in the intermediate and Senior Phase (Grades 4 to 9), describes the pedagogy of these two distinct subjects detailing how each should be taught and learned. The theory serving as the basis of any curriculum is not a matter of unassuming speculation. Curricula are entrenched in research and theoretical principles fundamentals that essentially include usually recognised and accepted action principles of the learning area's ethical and other directorial philosophical reflections. Upon such theoretical bases, curriculum praxis (practice) makes ever-new practical knowledge because of the particulars of the position governing both the curriculum and the educator and those served. As argued by RT Regelski praxis-based knowledge constantly takes a peculiar form for a particular practitioner but, notably, within the common theoretical, ethical, and philosophical stance of the profession. ${ }^{1}$ As a result, there are no customary method outcomes for any practitioner or for the overall profession. Nonetheless, for RT Regelski there are results but they are standard and might be "just standards of care" rooted in the profession's theoretical and ethical premises. SS education as such has developed no such shared action ideals concerning ends and so the issue of theory-guided practice or of a curriculum ethic remains ambiguous, even controversial. Hence RT Regelski referring to music teaching puts forward that it becomes problematic for curricula that lack ideals as the basis for ethical accountability, actual outcomes as they tend to be relevant only to the classroom rather than to the world outside school. For SS it means there are issues with the connection between the name of the learning area and therefore the praxis.

The praxis is in relation to integration pertaining to the teaching and learning of SS. The issue of integration is complex and is supported by some authors and interviewees in this study while others dispute using diverse reasons. But the question remains about the name as it depicts the learning area as one while in practice it is divided subjects. Thus, it is important to adopt RT Regelski's views of critical professionals in this instance. For him

1 RT Regelski, "On 'methodolatry' and music teaching as critical and reflective praxis", Philosophy of Music Education Review, 10(2), 2017, pp. 102-123. 
it allows ideology critique as it permits professionals to evaluate conditions that alienate them or learning areas to bring about 'right results' for students. ${ }^{2}$ Such outcomes require teachers not to teach as they were taught, but practice cooperative interactions between teachers, parents, community members, administrators and learners on valued outcomes SS has to produce. This is praxis reflection which focuses on action based SS curriculum reflecting the communities it serves and empowering learners with critical lifelong learning skills to engage in such a context. It is a curriculum that has outcomes based on common models from society that form action ideals. ${ }^{3}$ It is a suggestion for a SS curriculum that purports for lifelong education rather than only academic output. In the subject learners will be taught sciences of societies as the name depicts. This shows a curriculum that is interdisciplinary in nature as it allows for the integration of a diversity of knowledges. ${ }^{4}$ Hence the question that arises in this article is: Does the name SS reflect the practice of what the learning area stands for in its curricula?

In responding to the above question it is important to understand the term reflective praxis. According to Aristotle praxis refers to the practice of doing something which is committed to right living through the search of human good. ${ }^{5}$ Schwandt elucidates praxis as a word that is different from practice in the sense that it is used for a certain process of social action that is not instrumental as it does not deliver about unambiguous products that involve a kind of methodological capability. ${ }^{6}$ But Y Waghid sees praxis as a way of doing something that has moral and ethical implications. Educationally it is concerned with valuable output not focused into making action which has an end aim of producing a specific object but focused on lifelong learning which empowers learners with values and ethics that assist them in nation and self-building. Thus, praxis "is a form of 'doing action' precisely because its end can only be realised through action and can exist in action (discourse) itself". ${ }^{7}$ It means that SS praxis depends on cooperative consensus among all stakeholders about how the learning area can be taught to produce action ideals that are reflexive of its name. This indicates reflectivity as a condition to praxis because as an action it "involves critically examining one's personal and theoretical dispositions and, at the same time, investigating how one's personal and theoretical, commitments can transform patterns of critical

\footnotetext{
2 RT Regelski, “On 'methodolatry'..., Philosophy of Music Education Review, 10(2), 2017, p. 112.

3 RT Regelski, “Action learning”, Music Educators Journal, 69(6), 1983, pp. 55-57.

4 Y Waghid, Democratic education: Policy and praxis (Stellenbosch, Stellenbosch University Publishers, 2002), p. 69.

5 Y Waghid, Democratic education..., p. 69.

6 Y Waghid, Democratic education..., p. 64.

7 W Carr, cited in Y Waghid, Democratic education..., p.64.
} 
inquiry". ${ }^{8}$ As such reflective praxis focuses on encouraging people to engage in self-assessment in order to come up with practices that would bring change in people's understanding of themselves and their practices to produce human good in society. Hence, this article deals with the SS learning area as it is one of the official subjects taught in schools that can assist in promoting essentially worthwhile ends as it deals with social sciences. It helps learners understand people and the world in which they live. But there are gaps in the teaching and learning of the subject linked with its reflective practice which makes it not fully contribute to holistic standards of ethical care.

As an ex-teacher of History and head of department of Humanities (Geography and History) and currently a lecturer of Social Science Education who studied History and dealt with some Geographic themes at $\mathrm{PhD}$ level I have faced many challenges with the teaching and learning of the subject. The challenges I encounter are also subsequently experienced by the students I teach who have enrolled in the Post Graduate Diploma in Education (PGCE) (a one year teaching course which is normally done by students who obtained their three years Bachelor's degree). PGCE students are considered to be experts in both Geography and History as they are accepted in the course because they have a degree that has both subjects. In my personal communication with them they raised challenges pertaining to the management and administration of the subject and mentioned the discouragement which affects their love of the subject. ${ }^{9}$ They raise the issue of teachers who are not qualified to teach the subject and little time apportioned for the learning area as major hurdles. Some interviewees raised the pertinent issue of a divided subject that is integrated only though marks and not content. The powers that be are silent about integration of SS and how it could be done. Reform in SS has always been in developing the two subjects as separate entities but perhaps the call for authorities is to direct more energy on how integration can happen ${ }^{10}$, and put in place textbooks that adhere to that. This requires solutions that would assist in quality learning and teaching. As put by M Van Manen curriculum apprehensions are practical concerns and require practical decisions from educators. ${ }^{11}$ RT Regelski takes this further by suggesting that: ${ }^{12}$

$8 \quad$ Y Waghid, Democratic education..., p. 65.

9 MC Kgari-Masondo (Personal Collection) and D Mosina (Research Assistant), interviews, University of KwaZulu Natal Post Graduates Certificate in Education 2016 Social Science students, June 2016-November 2016.

10 SJ Thornton, "Geography in American History course", Phil Delta Kappan, 88/7, 2007, pp. 535-538.

11 M Van Manen, "Linking ways of knowing with ways of being practical", Curriculum inquiry, 6(3), 1977, pp. 205-228.

12 RT Regelski, "On 'methodolatry' ..., Philosophy of Music Education Review, 10(2), 2017, p. 102. 
A true profession is that praxis relies upon underlying theory and the fund of widely accepted practice-based knowledge generated by theory that is required to deal with the extensive variety of predictably unique problems and needs presented by those served. Teaching clearly deviates substantially from these conditions.

In this sense 'mischief' can explain the SS curriculum. The word SS does not carry with it the practical hurdles pertaining to the implementation of the subject. As entailed in the words of RV Bullough that, words bring mischievousness and words name worlds and form realities. ${ }^{13}$ SS in words depicts an integrated learning area but pedagogically it is not. The confusion is also evident at the university where I work - some lecturers are not certain what SS entails. It is always a question of whether it is History, and Geography or SS. These uncertainties stem from the reflective praxis of the implementation of the learning area in relation to its name which leaves a misconstrued sense of reality of the pedagogics of SS. This explains why SS has been plagued by intellectual skirmishes over its purpose, content and pedagogy since its commencement as a school subject in the early part of the $20^{\text {th }}$ century. Re-examining the name SS for the teaching of Geography and History from Grade 4 to 9 in SA is a an action discourse that is aligned with praxis reflection because, it is a critical inquiry compelled by the emancipatory concern, since its resolve is to contribute to change in people's understanding of themselves and their practices and thus frees them from the constraints of society. ${ }^{14}$

\section{A pedagogical "mischief"}

Globally, the past century has witnessed an increase in changes in History and Geography Education pedagogy and content. An interdisciplinary approach has been part of the debates concerning the teaching of the subjects. ${ }^{15}$ Though some scholars continue to promulgate studying and learning in a disciplinary ${ }^{16}$ fashion, on the contrary some current debates encourage interdisciplinarity. But, little has been done on how SS integration can occur in SA. Despite all the advances on improving SS education teaching there remain gaps or missing links in terms of the content taught and its relevance to the society it

13 RV Bullough, "Becoming a student of teaching", DA Breault \& R Breault, Experiencing Dewey: Insights for today's classroom (Routledge \& Kappa Delts Pi, New York, 2014).

14 H Giroux, Border crossing: Cultural workers and the politics of education (London, Routledge, 1992), pp. 30-40.

15 M Summers, A Childs, \& G Corney, "Education for sustainable development in initial teacher training: Issues for interdisciplinary collaboration", Environmental Education Research, 11(5), 2005, pp. 623-647 (available at http://www.tandfonline.com/doi/full, as accessed on 24 October 2017); D Lambert, \& J Morgan, Teaching Geography 11-18: A conceptual approach (McGraw-Hill Education, United Kingdom, 2010); Kgari-Masondo, "Incomplete history curriculum? Teaching socio-environmental history in SA High Schools. From an indigenous perspective", YesterdayぬToday, 10, 2013, pp. 101-124.

16 S Wineburg, Reading like a Historian: In American anthem (San Diego, CA, Holt Rinehart and Winston, 2005). 
caters for and makes the content not easily accessible to learners. Such missing links cause tension between the official SS taught in schools and unofficial pedagogical strides that learners acquire from the media, friends, family and in their personal experiences. Subsequently, the missing gaps would bring the subject matter and pedagogy in line with on-going research and it would ensure a rounded focused curriculum. Embracing an integrated SS curriculum is critical as it will deal with the purpose of History and Geography; that of imparting the skill of multi-perspectivity and values aligned with nation building. In divergence CAPS only indicates multiperspectivity as a skill for History teaching. ${ }^{17}$ This is an important point as it shows that the stipulation of CAPS of an SS curriculum that is divided but designed to complement the knowledge (content, skills and concepts) outlined in each does not reflect the praxis it envisaged. The important argument that CAPS raises is that, the SS curriculum "aims to provide opportunities for learners to look at their own worlds with fresh, critical eyes". ${ }^{18}$ This is a noble vision which challenges the SS curriculum to be in line with current debates in the SS on inter-disciplinarily in research and policy making. The debates in SS teaching in SA have missed some important aspects aligned with the teaching and learning of the subject such as: the reflective praxis, integration, and addressing the content in a multidisciplinary way. This shows that there still remains much work to be done in ensuring that SS is kept on par with research and produces quality content for learners and teachers in schools.

From literature surveyed there is a dearth on ways of integrating SS in South African schools. As far as the present researcher has ascertained no study has been undertaken critiquing the name conferred to SS by investigating whether it is aligned with the pedagogical practices of the subject. SS focuses on social sciences which is an integrated subject about diverse epistemologies and has to be taught as such. My applications insinuate an innovative kind of SS for the academic study of Geography and History in an integrated manner by ensuring all themes in History or Geography are taught drawing from the two learning areas in a collaborative manner.

\section{Method and approach}

In an analysis of SS as an integrated subject I rely on interviews and

17 Department of Basic Education, Republic of SA, National Curriculum Statement. Curriculum and Assessment Policy Statement (CAPS). National Curriculum Assessment Statement for Social Science Senior Phase, (Pretoria, Government Printing Works, 2011), pp. 5, 10-12.

18 Department of Basic Education, Republic of SA, Curriculum and Assessment Policy Statement (CAPS): Social Sciences Senior Phase, Final, (no date), p. 7. 
documented literature. The research problem in this study has pointed towards the use of the qualitative approach as the strategy of inquiry. That being so, it follows then that the research design from the current study has to come from a number of alternatives skewed towards the qualitative approach. For the purpose of this study, the qualitative, naturalistic approach which is phenomenological is used, because it allows the researcher to produce rich information and to understand community beliefs from within. ${ }^{19}$ The goal is not to understand phenomenon with pre-existing sets of formulae used as a criterion for measurement. Qualitative researchers generate data in the form of written or spoken language, or in the form of observations that are recorded in language and analyse the data by identifying themes. ${ }^{20}$ Another reason why this study falls within a qualitative approach is because it allows me to do an in-depth analysis to understand the phenomenon under study. This links well with the phenomenological methodology as it allows the researcher to produce rich information and to understand the phenomenon under study from within and suspend judgements about its beliefs or practices ${ }^{21}$ as the use of discourse analysis of day to day language use of trainee teachers' pedagogy in SS. The methods allow each of the participant's accounts to be examined in great detail as an entity in its own right before a move to more general claims in a narrative account that includes detailed extracts from other participants' accounts. ${ }^{22}$ As the study is qualitative a case study sits comfortably with the approach because it "offers a multi-perspective analysis in which the researcher considers not just the voice and perspective of one or two participants in a situation, but also the views of other relevant groups of actors and the interaction between them". ${ }^{23}$ The focus of this article is on teachers' perceptions of SS integration and therefore the way forward. The study is therefore aligned to elicit deep information from the teachers as they show or tell their lived experiences which later turns to their thoughts as they suggest strategies to avert the challenges. As a result the critical paradigm is employed in this study because it is driven by emancipatory interest as the SS curriculum implementation is flawed with challenges and the practitioners

19 K Durrheim \& D Painter, "Collecting quantitative data: Sampling and measuring", M Terre Blanche, K Durrheim \& D Painter (eds.), Research in practice: Applied methods for Social Sciences (Cape Town, University of Cape Town Press, 2006), pp. 131-159; MT Blanche et.al, Research in practice (Cape Town, University of Cape Town Press, 2006), p. 132; L Cohen, L Manion, \& K Morrison, Research methods in education (London and New York, Routledge Taylor \& Francis group, 2011), p. 18.

20 MT Blanche et.al, Research in practice..., pp. 132-159.

21 L Cohen et.al, Research methods in education..., p. 18.

$22 \mathrm{~J}$ Tosh, The pursuit of History: Aims, methods \& new directions in the study of modern History (London and New York, Longman, 2015), pp. 220-221.

23 J Nieuwenhuis, "Qualitative research designs and data gathering techniques", J Maree (ed.), First steps in research (Pretoria, Van Schaik Publishers, 2007), p. 75. 
need agency in transformation of the subject to reflect the practices it purports. The reflective praxis of the SS curriculum by embracing integration of History into Geography and vice versa; will be a pilgrimage of ensuring depth required in the study of SS. This means that the proposal in this article is valid as it is yet another technique of helping learners acquire knowledge from diverse societies in SS. In order to understand how knowledge development and the curriculum functions $Y$ Waghid argues that, it is acquired from mindful organised rational human experience, and also other traditions of the world which is placed under diverse disciplines. ${ }^{24}$ On the other hand A Bernstein and F Provost argue that the results of such knowledge processes should be ranked differently for diverse users because of varied techniques people use in data construction. ${ }^{25}$ As such the process of knowledge production becomes complex since researchers have to construct it, then it goes to policy makers to be decontextualized, from here textbooks and training institutions eventually duplicate such data, when it reaches teachers it becomes reproduction. Hence M Gibbons et.al suggests two modes of knowledge development academically. Mode one focuses on structured and organised knowledge production which draws from disciplinary style of knowledge construction which is not reflective of society it serves as it is rigidly based on science as the only standard to measure progress and authenticity. ${ }^{26}$ While mode two focuses on an extension of mode one and is mainly based on rational human experience and is transdisciplinary in approach drawing from diverse epistemologies. ${ }^{27}$ In this sense mode two is socially accountable in terms of knowledge development because it embraces the fact that "the issue on which research is based cannot be answered in scientific and technical terms only. This means that, for mode two to be more effective it requires mode one which focuses on a sound discipline based curriculum. This conjectures that any curriculum that is sound has to reflect the praxis of its society. As suggested by AM Rocca curriculum transformation is very complex but doable and they have concerns that are practical requiring practical decisions. ${ }^{28}$

24 Y Waghid, Democratic education..., p. 67.

25 A Bernstein \& F Provost, "An intelligent assistant for the knowledge discovery process" (Paper, Centre for Digital Economy Research, Sten School of Business, 2001(available at https://archive.nyu.edu/jspui/bitstream, as accessed on 27 October 2017).

26 M Gibbons, C Limoges, H Nowotny, S Schwartzman, P Scott, \& M Trow, The new production of knowledge: The dynamics of science and research in contemporary societies (Sage, 1994).

27 Y Waghid, Democratic education..., p. 67.

28 AM Rocca, "Integrating History and Geography: Classroom teacher's idea notebook", Social Education, 58(2), 1994, pp. 114-116. 
The approach adopted in this article does not refute the significance of SS as is but proposes ways of pushing to a balance of M Gibbons' two modes of knowledge development within the subject. The curriculum, and teaching of the subject have to embrace a strong discipline of History and Geography but in the same note draw from trans-disciplines to ensure quality and sound knowledge production so it reflect the name SS. Trans-discipline is pivotal but has to be grounded also in understanding one's discipline as a distinct learning area which is not a stand-alone as an island but as a member of the other disciplines. This surmises that the rigidity in SS through its strict routines linked with pedagogical policies has limited the teaching and learning in the subject to flourish to the greatest heights. As put by RV Bullough that "maintaining routines becomes the end of education rather than a means for achievement" ${ }^{29}$ It is a call for curricula such as SS to engage in breaking the norm and transform for progress and not for change sake and engage with mischiefs surrounding even the words accorded to its name. The use of critical discourse, drawing from interviews and secondary data will help in illuminating the proposal further.

A case study of twenty PGCE students from the University of KwaZulu Natal was interviewed in 2016 on SS integration. Ethical clearance to undertake the research was obtained from the University of KwaZulu- Natal Ethics Committee on the $29^{\text {th }}$ of August 2016 under protocol reference number HSS/1295/016M. Their names in this article are pseudo names to protect their identity for ethical reasons. Most of the trainee teachers interviewed were Black and they all studied Geography and History at school and at University. At Edgewood Campus, Blacks are the majority as my sample depicts. Hence the views of the interviewees declare that indigenous knowledge (IK) has to be integrated in SS so as to ensure rounded understanding for learners. In this project the conceptualisation of indigenous and indigenous knowledge moves away from Hirst's views of perceiving indigenous people as only African people and not people of other continents which includes their knowledge thereof. ${ }^{30}$ The views of D Njiraine, DD Ocholla and OB Onyancha fit appropriately with this article as it universalises the concept of indigenous and indigenous knowledge - they opine that the words are usually used when referring to people who inhabited a geographic location before it was colonized and this

29 RV Bullough, “Becoming a student...”, DA Breault \& R Breault, Experiencing Dewey..., p. 79.

30 M Hirst, "Critically engaging indigenous knowledge systems", South African Museum Association Bulletin, 28(1), 2002, pp. 3-7. 
is aligned with their knowledge of such communities. ${ }^{31}$ In this article the word "system" is not used when referring to IK because it does not only reify $\mathrm{IK}$, but also diminishes it to a treasure box of some clever philosophies that have been exhumed from an exceptional source (indigenous communities). ${ }^{32}$ Equally since SS deals with human issues their knowledge is pivotal and must be revered as part of the learning area and such content is normally lacking in the curriculum. ${ }^{33}$ SS has indigenous themes ${ }^{34}$ and it makes sense that they have to be studied in a decolonised fashion which is part of the current debates on curriculum transformation and fits well with integration proposed in this article. As such the recent development worldwide of an education system that has to be economically aligned is problematic because it absurdly or incongruously makes people participate in the oppression of aspects of the curriculum content and approach that ought to ensure quality teaching and learning such as oversight of integration of learning areas and also IK and the people believing in it. ${ }^{35}$ Such omissions are normally done citing financial burden as the reason and in the process quality teaching and learning are compromised. ${ }^{36}$

This article seeks to investigate the SA schools SS curricula from Grade 4 to 9 and pedagogical practices in classroom teaching to indicate the deficiencies embedded in the current study of the learning area. It is the duty of Social Scientists to report things as they are, hence the article tries to show the contradictions between the name SS and the pedagogics behind the learning area. "Multi-perspectivity" is one of the pertinent SS concepts highlighted by the CAPS Grade 4 to 9 curriculum and it is also lacking in the pedagogical and construction of SS textbooks. The CAPS document defines "multi-perspectivity" as the many ways of looking at the same thing. Such perspectives may arise because of different points of view of people in the past according to their position in society, the different ways in which

31 D Njiraine, D Ocholla \& OB Onyancha, "Indigenous knowledge research in SA and Kenya: An informetric study”, Indilinga: African Journal of Indigenous Knowledge Systems, 9(2), 2010, pp. 194-210.

32 LS Masuku van Damme, \& EF Neluvhalani, "Indigenous knowledge in environmental education processes perspectives on a growing research arena”, Environmental Education Research, 10(3), 2004, pp. 353-370.

33 MC Kgari-Masondo, "Incomplete history curriculum? ...”, Yesterday\& Today, 10, 2013, pp. 101-124.

34 These are themes that deal with indigenous people and require the knowledge process from their own context. For example if one teaches on Ghandi or Indian slaves in SA we have to draw from the Indian context - their knowledge process taking into cognizance the diverse Indian beliefs within the culture. Similarly if is African indigenous themes like issues of land or content relating to them it is important to draw from the knowledge of the group one studies and not impose western standards in studying such communities who were colonised and subjugated historically.

35 LS Masuku van Damme \& EF Nehluvhalani, "Indigenous knowledge in environmental education processes perspectives...", Environmental Education Research, 10(3), 2010, p. 356.

36 MC Shug \& B Cross, "The dark side of curriculum integration...", The Social Studies, 1998, p. 56. 
Social Scientists have written about them, and the different ways in which people today see the actions and behaviour of people of the past. ${ }^{37}$ This is part of the integration that SS lacks and is betrayed by its name that purports the study of both History and Geography but practically it is not done so.

\section{The history of SS}

To locate the history of SS in SA it is important to trace it back internationally as the country was colonised by Britain and it embraced western standards in its education spheres. According to EW Ross the learning area SS can be traced back to when it was first used as a school subject by TJ Jones in 1905 in his article that was expanded into a book "Social Studies in the Hampton Curriculum". ${ }^{38}$ In this book his concern was to enlighten Americans into understanding that young African and Native Americans needed to understand the powers and the social operations for them to be fully integrated into the society of their country. In this instance he was able to detect the pedagogical mischiefs as the learning area was not reflective of the American social context. He was inferring that SS curriculum has to teach about social order and social forces operational within it and techniques to drive and respond to that social authority. As a result, his call was answered in 1916 when the National Education Association Committee created SS as an established scope and sequence of courses that define the contemporary curriculum in America. As such in SA historically Geography and History were taught separately until during the post-apartheid period where attempts were made to integrate the subject under Outcomes Based Education (OBE). ${ }^{39}$ But there still remains gabs as SS still does not fully embrace in its pedagogy that centres on sciences of all the community it purports to serve.

In SA during the apartheid dispensation the Geography aspect of SS was taught as a study of the physical rather than the human world ${ }^{40}$ and History was based on events and great leaders. The content was Eurocentric and IK has been ignored, or if integrated it was taught using western epistemology lens by downplaying IK. The SS curriculum was taught as Geographic determinism propagating the view that the natural environment dictates how people

37 Department of Basic Education, Republic of SA, National Curriculum Statement..., pp. 10-12.

38 EW Ross, The Social Studies Curriculum: Purposes problems, and possibilities (University of New York Press, Albany, 2006).

39 D Wilmot, "The inception phase of a case study of outcomes-based education assessment policy in the Human and Social Sciences Learning Area of C2005", South African Journal of Education, 23(4), 2003, pp. 313-318.

40 AM Rocca, "Integrating History and Geography...," Social Education, 58(2), 1994, p. 536. 
live. ${ }^{41}$ This interpretation adheres to the grand theorists that disregard human agency and power. The view ignores the fact that people living in the same settlement can respond differently to their environment because of different forces such as culture, religion, class, race and so forth. The new SA in the late 1990s as part of its Curriculum 2005 program introduced curriculums that tried to accommodate the knowledges of all people but this is still a dream as this article tries to elucidate. OBE was one of such curriculums and it brought integration in terms of the subjects History and Geography but many teachers were not trained to master both subjects and found integration difficult. ${ }^{42}$ Moreover Historians and Geographers feared for the independence of their subjects. They felt that their subjects will be subsumed into the other learning areas ${ }^{43}$ which is a cause for concern because a learning area must not survive because of practitioner's fears of losing their jobs but because of its efficacy and relevance. Hence, under CAPS the policy makers reverted to a disciplinary based SS curriculum and integration occurs through combining assessments of learners' end of the term. But the latter curriculums like the Revised National Curriculum Statement (NCS) (Grades R-9) between 2000-2002 and currently CAPS took another turn of integration whereby knowledges of those previously disadvantaged; indigenous people is condoned as important. But still a problem remains - how should IK be integrated in the curriculum?

In the late $20^{\text {th }}$ and $21^{\text {st }}$ centuries SS under CAPS began to be taught more for meaning not memorisation. The pedagogical methods began to be modernised whereby information technology started to be used in teaching. Application skills have been employed especially in the $21^{\text {st }}$ century to empower learners with creative, analytical and critical skills. Human agency serves as a key in the teaching and learning of the subject. Hence the segment of Geography focused more on Human Geography and became a focus as well as other Geography sections. But such content is still taught from a Eurocentric perspective. ${ }^{44}$ With regard to shifts in the History part of SS, AM Rocco argues that map work began to be used to make History incidents more meaningful and more memorable. But still SS has not enjoyed the integration its name stands for - embrace knowledges of communities it serves and also embrace multidiciplinarity in its pedagogy.

41 AM Rocca, "Integrating History and Geography...", Social Education, 58(2), 1994, p. 537.

42 L Chisholm, et.al, A South African curriculum for the twenty first century, Report of the review committee on Curriculum, (2005).

43 AM Rocca, "Integrating History and Geography...", Social Education, 58(2), 1994, p. 36.

44 LS Masuku van Damme \& EF Nehluvhalani, "Indigenous Knowledge in environmental education...", Environmental Education Research, 10(3), 2010, pp. 353-370 . 
Research has shown that since its inception the SS curriculum has been plagued by intellectual battles over its purpose, content and pedagogy and these disagreements have shaped the learning area and energised it. ${ }^{45}$ Since curriculum development is work in progress M Weber's "ideal type" hypothesis is pivotal and relevant in dealing with the historical drawbacks of SS pedagogy and curriculum. It calls for an implementation of the new "ideal type" SS curriculum. ${ }^{46}$ This will be a great transformation to the SS curriculum received from the early $20^{\text {th }}$ century to-date. As M Weber puts it:

An ideal type is a conceptual formulation in Social Science that is regarded as a working hypothesis until its realistic worth has been demonstrated by observation.

\section{Why not integration?}

Many reasons are placed by scholars about unconstructiveness of integration of SS, some are valid while some are mischievous. ${ }^{47}$ According to MC Shug and $\mathrm{B}$ Cross the benefits of curriculum integration are not worth the costs because: ${ }^{48}$

The costs of curriculum integration are high, real, and certain. Conjecturing that the benefits of integration are low, vague, and difficult to measure. Meaningful curriculum integration requires a large investment in staff development and planning.

His view suggests that SS cannot be integrated because of financial burdens related to resources, retraining of staff and more so not perceived as beneficial. The interviewees who disprove integration mentioned the fact that the retraining of teachers would be required as many teachers are not specialists in both subjects. As opined by one informant, Ms Interesting: "I feel it is easier for learners to leave SS as is because they are able to focus on one's subject from an expert teacher at a time. For an example they will do History at a time then jump to Geography". This means that strong discipline content as put by $\mathrm{M}$ Gibbons mode one knowledge construction philosophy is key when disapproving integration.

Another reason preventing integration is job security. When SS was introduced both practitioners of History and Geography feared that their disciplines

45 EW Ross, The Social Studies Curriculum..., p. 19; AM Rocca, "Integrating History and Geography...", Social Education, 58(2), 1994, pp. 114-16.

46 M van Manen, "Linking ways of knowing...", Curriculum Inquiry, 6(3), 1977, p. 209.

47 MC Shug \& B Cross, "The dark side of curriculum integration in Social Science”, The Social Studies, 89, 1998, pp. $54-57$

48 MC Shug \& B Cross, "The dark side of curriculum integration...”, The Social Studies, 89, 1998, p. 56. 
would be subsumed into SS. ${ }^{49}$ It is because through globalisation economic benefits are the core of societal developments and that has an impact on the teaching and learning of SS. The new trend globally of an education system that has to be economically aligned is problematic because it paradoxically or ironically makes people participate in the oppression of what SS has to embrace: all knowledges of societies (like IK). ${ }^{50}$ This means that job security is normally the core consideration when it has to deal with the reorganisation of the curriculum. As put by AM Rocca the current curriculum system echoes almost a mechanical value system as it has a means - end rationality that styles an economic model. ${ }^{51}$ But what about the reflective praxis of the SS curriculum? Considering M Weber's notions on "ideal type" MC Shug and B Cross' views are not valid because: the "ideal type" is not just a fictional mental construct it exists and is an employed proposition until its realistic value has been established by observation. ${ }^{52}$

Thus, can we conclude with MC Shug and B Cross' views that the benefits of SS curriculum are low and are not worth the costs? Using M Weber's "ideal type" curriculum, any re-construction of any learning area to achieve the ideal is worth pursuing because real curricula is ever changing for the benefit of progress, societal interests and nation building. Hence, EW Ross argues that, SS curriculum content is the most inclusive of all subjects.

\section{SS textbooks and integration}

Research and the fieldwork conducted for this study indicates that in SA content representation in textbooks is critical to understanding schooling as textbooks are mostly used as part of the curriculum especially in a SS classroom. According to RS Blumberg they occupy up to 80 percent of classroom time. ${ }^{53}$ The curriculum requires specific content to be completed and mainly the textbook writers use the curriculum to ensure that it tallies with themes prescribed. Worst of all is the official endorsement that only accepted books that are in line with the curriculum are the ones recommended to schools. This then renders textbooks to be indispensable sources for teaching and learning. Subsequently, this has dire ramifications to creativity, critical thinking, multi-

49 AM Rocca, "Integrating History and Geography...", Social Education, 58(2), 1994, pp. 114-116.

50 LS Masuku van Damme \& EF Nehluvhalani, "Indigenous Knowledge in environmental education...", Environmental Education Research, 10(3), 2010, p. 356.

51 AM Rocca, "Integrating History and Geography...", Social Education, 58(2), 1994, pp.114-116.

52 M Van Manen, "Linking ways of knowing...", Curriculum Inquiry, 6(3), 1977, p. 206.

53 RS Blumberg, "The invisible obstacle to education equality: Gender bias in textbooks", Prospects: Quarterly Review of Education, 38(3), 2008, pp. 345-61. 
perspectivity and the fact that knowledge in textbooks should always be in line with current research to deal with missing links that may occur. This explains why from literature surveyed no textbook has been written in SA that integrates SS. Hence S Wineburg argues that, a well-known problem in History (and SS my emphasis) education is that educators customarily see their prime duty being that of "covering" an enormous prescribed curriculum with the assigned textbook. ${ }^{54}$

An analysis of the curriculum and the textbooks' representations of SS is important, because non-integration as it exists in the contemporary SS curriculum and the teaching of SS can perpetuate misrepresentations of SS and bias towards such content. This is a call for the curriculum to have as its second order concepts ${ }^{55}$ a "border crossing pedagogy" that would allow for the integration of SS which consequently has ramifications to textbook writing. According to H Giroux "border pedagogy" recognises and actively promotes the recognition of 'other histories' and 'other geographies' (my emphasis) and that venture on its own also aids in the integration of Geography into History and vice versa. ${ }^{56}$ As shown in literature the learning of SS should be an enquiry for students so that they have the opportunity to develop manifold perspectives, investigation skills and critical thinking habits. ${ }^{57}$ This implies that communication between textbooks, curriculum and contemporary research can assist in impacting on effective SS curriculum and textbook writing.

It is a call for policy makers and also textbook writers of SS to ensure reflective praxis in the SS subject by adopting progressive solutions to deal with the mischiefs detected in the curriculum by ensuring integration in their writings - and include the social, physiological, psychological, economic, cultural, and environmental aspects as part of the studies of societies entailed in the SS curriculum. This also includes the integration of diverse knowledge and not only western epistemology. SS must not be written in an uncritical manner as if it is static and is not linked with structures of society like Geography on its own as most of the themes are detached from studies of societies hence it needs History to make-up for the drawback. It has to be shown to students

54 S Wineburg, Historical thinking and other unnatural acts: Charting the future of teaching the past (PA, Temple University Press, 2001); S Wineburg, Reading like a Historian... .

55 Second order concepts like; empathy, significance, cause and consequence, continuity and change, indigenous knowledge, environment, gender and class. These are threshold concepts that assists learners to understand SS.

56 H Giroux, Border Crossing..., pp. 30-40.

57 K Barton \& L Levstik, "Why don't more history teachers engage students in interpretations?", W Parker, Social Studies today, research and practice (New York, Routledge, 2010), pp. 34-42; B van Sledright, "What does it mean to think historically ... and how do you teach it?", W Parker, Social studies today, research and practice (New York, Routledge, 2010), pp. 113-120. 
that structures of society are social constructs and are invented. ${ }^{58}$ This is the appreciation of Turner's insight that the master key to History is to be found in the relation of Geography to that History. ${ }^{59}$ This then is cause for concern as put by Barnard (2001) that such "curricula and textbooks used within schools deserve careful examination, as they both represent the political and social climate of the time in which they were written" ${ }^{60}$ But in SS such textbooks need to be rewritten because of the missing links identified in this article. This is supported by AM Rocca by stating that, SS textbooks are found lacking in offering detailed information in History and Geography. Thus missing links in any curriculum have a bearing in textbook constructions, and can cause tension in what is perceived as official and unofficial SS learning area which if not dealt with can further contribute to problems in people's understanding of SS and hamper effective engagement in nation building which is critical when teaching and learning sciences about societies (SS).

\section{Reflective praxis: SS or Geography and History?}

Research on SS integration does not identify the problems relating to the adaptation on the name of the learning area to the two separate subjects it embraces; but identifies economic ${ }^{61}$, political ${ }^{62}$ and social ${ }^{63}$ reasons. The concept SS as it stands in the CAPS is an anti-reflective practice model as it does not speak to the sciences of society it serves drawing from both subjects. Drawing from RT Regelski's suggestion on music curriculum SS also needs to "use disciplined critical thinking derived from supporting disciplines and curriculum" and also embrace the fact that it is "the responsibility of each member of a self-critical community where professional competence is judged in terms of benefits for those served" ${ }^{64}$ The Sesotho idiom explains this fact better - leina leile borelong meaning that it is important to name a person or object what and who you want it to turn into. A question arises - does SS reflect its name in practice?

The majority of interviewees argue that SS does not reflect the practice of the subject pedagogically. ${ }^{65}$ To use LS Mitchell's words it is "dis-connection"

58 P Gilroy, "Race ends here", Ethnic and Racial Studies, 21(5), 1998, p. 842.

59 AM Rocca," Integrating History and Geography...”, Social Education, 58(2), 1994, pp. 114-116.

60 CE Schrader \& CM, Wotipka, "History transformed?...", Feminist Formations, 23(3), 2011, p. 69.

61 MC Schug \& B Cross, “The dark side of curriculum integration...", The Social Studies, p. 57.

62 SJ Thornton, "Geography in American History course", Phi Delta Kappan, 88(7), 2007, pp. 535-536.

63 SJ Thornton, "Geography in American History course”, Phi Delta Kappan, 88(7), 2007, p. 535.

64 RT Regelski, “On 'methodolatry' ..., Philosophy of Music Education Review, 10(2), 2017, p. 113.

65 MC Kgari-Masondo (Personal Collection) and D Mosina (Research Assistant), interview, PGCE student, 20 September 2016. 
because it portrays a world of disconnected "end-products" ${ }^{66}$ It suggests that the teaching and learning of SS portrays a disengaged learning area and has pedagogical disjuncture because the teaching and learning objectives are not in line with its name. This is taken further by an interviewee Mzele that: ${ }^{67}$

Social Science learning area could be defined as a discipline that integrates both the Geographic and the Historic disciplines. My view on this current SS being separated into specific disciplines is of great misfortune. This being, because in teaching History, Geography basically needs to be incorporated and vice versa.

Issues related to integration cannot be used as an excuse to betray what SS has to resemble as a learning area - united subject that focuses on sciences of society. Excuses posed by scholars like SJ Thornton that teachers are rarely knowledgeable in both SS subjects ${ }^{68}$ and MC Shug and B Cross' views about financial burden of integration ${ }^{69}$ hold water but cannot be used to misrepresent the learning area pedagogically. As is, SS appears as if the subjects (History and Geography) are in competition with each other. As MC Schug and B Cross have argued students perform badly in SS because of instruction in discipline. ${ }^{70}$ But, in my SS modules at the University of KwaZulu- Natal, I employ integration. From January 2015 I engaged in a new venture of trying to revamp the SS curriculum and deal with some of the mischiefs in the learning area. My courses are organised in such a way that I teach students how to teach the current SS curriculum and the new "ideal type" SS where integration can be applied. ${ }^{71}$ This practice has worked exceptionally well and shows that debates on integration in SS in SA have to be activated so as we develop the subject to its pinnacle and make history in this $21^{\text {st }}$ century. Some of the missing gaps in the curriculum like indigenous knowledge, and environmental issues are immersed in the teaching and learning of SS because

66 LS Mitchelle Young Geographers: How they explore the world and how they map the world, 4 (New York, Bank Street College of Education, 1991), pp. 6-7.

67 MC Kgari-Masondo (Personal Collection) and D Mosina (Research Assistant), interview, Mzele, 28 September 2016.

68 SJ Thornton, "Geography...", Phi Delta Kappan, 88(7), 2007, p. 538.

69 MC Schug \& B Cross, "The dark side of curriculum integration...", The Social Studies, p. 57.

70 MC Schug \& B Cross, "The dark side of curriculum integration...", The Social Studies, p. 55.

71 I focus on History themes as they have stories behind and then use the themes to relate with the Geographical theme that can suit the content chosen in History. For example: The Soweto Uprising here learners are focused on causes, course and results of the strike. I then encourage my students to teach map work theories relating to the theme. Also climatology fits well as a teacher can teach theories around climatology and apply to Soweto while in the process of teaching about the Historical content of the uprising. Population Geography also suits well as here learners can learn about the population in Soweto in 1971 and the migration process. This I ask my students to apply in any theme they can find that can embrace both subjects. The students interviewed applied the principles in their year of PGCE and concurred that during their teaching practice they found the application doable. Though others found the practice difficult at times because teachers in schools did not allow them as the focus is on discipline rather than transdisciplinary approach. 
they are part of the learning area. ${ }^{72}$ As succinctly reiterated by an interviewee by not integrating SS it is "missing out on an opportunity to add value to lessons with extra context". ${ }^{73}$ Another informant, Bubbly mentioned that, the separate delivery of SS is not appropriate because learners have to understand how the two subjects (History and Geography) relate to each other. ${ }^{74}$ This means that, for reflective praxis to be done properly it has to start with the name of the learning area, to the curriculum planning, and implementation. Integration of Geography into History and vice versa would not only increase the amount of significant geographic content taught but also enrich the History subject as shown elsewhere in the article. This brings to the fore another important debate of introducing SS right through to matric and also allowing Geography and History to be taught separately.

IK has powerful idioms illustrating important outputs of integration. The idiom in isiZulu-izandlaziyagezana and seTswana mabogo dinku a thebana (hands washes each other) illustrates co-operation. Unity and collaboration are important. In terms of SS it means for the subject to reflect on its practice it has to be taught and organised in a collaborated fashion. To use MC Schug and B Cross' words: ${ }^{75}$

Curriculum integration provides a means to teach academic content in different ways. Integration does not replace, ignore, or reduce the academic content. Integration is not the end but rather a means to teach academic content.

\section{Integration of SS: Border Crossing Curriculum}

The integration of SS requires attention of policy makers and educators urgently. Authorities have been silent about how this could be done. A systematic curriculum development including materials needs to ensure integration in SS as an isolated phenomenon. Naturally educators who encompass the knowledge of Geography and History would do a great job in integrating the two subjects together for themselves. But college and university courses on the two subjects seldom seem to engage in integration. Most History teachers have no qualification in Geography and vice versa and they

72 Some of the themes within the learning area have critical gaps that require filling. They lack second order concepts or threshold concepts used in SS. For example; environment is missing in History teaching and learning. In Geography issues of History of themes is missing. Both subject lack focus on indigenous knowledge if it is used it is minimal.

73 MC Kgari-Masondo (Personal Collection) and D Mosina (Research Assistant), interview, Mr Vuyo, 28 September 2016.

74 MC Kgari-Masondo (Personal Collection) and D Mosina (Research Assistant), interview, Bubbly, 28 September 2016.

75 MC Schug \& B Cross, “The dark side of curriculum integration...”, The Social Studies, p. 56. 
need ready-made SS materials to assist them. ${ }^{76}$ Though complex, interviewees who learnt about and practically employed it argue that it is doable. The reports of studies of $G$ Vars support integration ${ }^{77}$ meaning that collaboration is attainable though challenging. It just needs committed practitioners of SS who are willing to engage in a "border crossing" strategy as the crossing deals with contradictions and allows for creative solutions thereof.

Research on SS integration has shown tensions in SS teaching and understanding which can be termed as competing SS. ${ }^{78}$ This indicates that diverse groups in society fight for the recognition and acceptance thus ensuring that they fight for a certain History and Geography to be recognized (official SS) and another to be pushed to the periphery (unofficial SS). Therefore, SS classrooms end up faced with missing links as teachers and students grapple with what is acceptable and unacceptable SS. This indicates that there is a pivotal connection between official and unofficial SS and this relationship has a bearing upon students and teachers of SS. This brings contradiction to learners and educators because officially SS is one learning area that is integrated as the name of the learning area confirms but practically it is divided through teaching and academic performance of learners and also amalgamated when teachers have to combine the summative assessments to make it SS.

Using A Low-Beer ${ }^{79}$ and R Phillips' ${ }^{80}$ analysis of official history in this instance, official SS is content that is taught in schools, and is what influences a child in the community, media, space lingua and through heritage sites. The content is eventually decided by the state and teachers are legally obliged to teach all prescribed topics of the official SS in the curriculum. Political power informs what has to be included in the SS curriculum. Hence A Low-Beer maintains that official history is led by political economic power and in modern societies it is institutionalized. On the other hand unofficial Geography and History brings to the fore tension towards what is taught in the SS curriculum. Nonetheless, the mischief of calling the subject SS yet it is not taught in an integrated fashion is noticeable and creates pedagogical tension embroiled with missing links. Teachers are not empowered to deal

76 MC Kgari-Masondo (Personal Collection) and D Mosina (Research Assistant), interviews, African Diks, Old Soul, Passionate, Study, Beautiful, Focused, No name, 26 September 2016 and Interesting, 28 September 2016.

77 G Vars, "Integrated curriculum in historical perspective", Education Leadership, 49(2), 1991, pp. 14-15.

78 F Furedi, Mythical past, elusive future: History and society in an anxious age (London, Pluto Press, 1992), p. 8; MC Schug \& B Cross, "The dark side of curriculum integration...”, The Social Studies, p. 55.

79 A Low-Beer, "School history, national history and the issue of national identity", International Journal of Historical Learning Teaching and Research, 3(1), 2003, pp. 1-6.

80 R Phillips, Reflective teaching of History 11-18: Meeting standards and applying research (A\&C Black, 2002). 
with such a puzzle. Unofficial SS thus, finds its domain at the gaps of social life, places and concerns. The powerful images people find in the media, society, special languages and heritage sites gathered outside the official environment have profound implications for the ways in which children are influenced and socialized which causes the state to re-conceptualize the way SS is taught. Hence H Kaye (1996) argues that such History is normally feared because of its ideological and cultural significance. ${ }^{81}$ Similarly in the Geography subject such competing knowledge has been identified by A Nyong, F Adesina, and B Elasha in their article on climate change mitigation and adaptation strategies. ${ }^{82}$ They illustrate and also suggest that, incorporating IK can enhance the development of sustainable climate change mitigation and adaptation strategies because of the richness in local content, relevance to local people.

A widespread literature has been written on the teaching of the official SS curriculum. But there is a dearth of investigation on how to construct an integrated SS and how to teach it. The unofficial SS embraces the "ideal type" curriculum envisaged in this article that must be drawn from the unofficial to the official teaching and learning of SS. Hence, R Phillips maintains that: ${ }^{83}$

The dimensions and boundaries of the 'unofficial' need to be explored in greater detail. By considering the symbols, images, versions, texts, institutions and media which bombard children daily with images of the past. It requires consideration of their potential effects and the ways in which they relate to the 'official' versions.

In terms of SS pedagogy it implies that, the unrecognized integration of Geography into History and vice versa requires recognition so as to bridge the gaps learners engage with outside the classroom whereby the way they learn about society is not divided but integrated. As put by MC Schug and B Cross: ${ }^{84}$

Advocates of integrated curriculum never tire of repeating the claim that people in real jobs, in the real world, rarely solve problems that fit neatly into narrow categories suggested by academic subjects. Real people, in real jobs, use communication and problem-solving skills that cut across disciplines.

The main impact of teaching SS in a divided manner is the eruption of conflicting views; and can cause confusion to students if mischief of the

81 H Kaye, Why do ruling classes fear History \& other essays (London, Macmillan, 1996).

82 A Nyong, F Adesina, \& B Elasha, "The value of indigenous knowledge in climate change mitigation and adaptation strategies in the African Sahel", Mitigation and Adaptation Strategies for Global Change, 12(5), 2007, pp. 787-797.

83 R Phillips, "Contesting the past, constructing the future: History, identity and politics in schools", British Journal of Education Studies, 46(1), 1998, p. 45.

84 MC Shug \& B Cross, "The dark side of curriculum integration...", The Social Studies, 1998, pp. 55-56. 
pedagogy is not addressed by all concerned. This can lead to problems in understanding SS as put by an interviewee that, the negative part of nonintegration of SS develops students who are not constructive as they are faced with unsolved mysteries of a subject that is integrative from its title but content is divided. ${ }^{85}$ She mentioned the fact that calculations are there in Geography and are rigorous pertaining maps but in History there is none but students also deal with places and maps. Since the SS curriculum does cater for the teaching and challenges of the contradictions in SS, students will not be empowered with ways and skills of dealing with the missing links within the subject. This is exacerbated by the overloaded SS curriculum which forces teachers to teach Geography and History for two terms. ${ }^{86}$

"Cultural border crossings" ${ }^{77}$ pedagogy is important here because it empowers the teacher with skills to help students to understand diversity and multiculturalism. In the process students will best understand their identity as South Africans in a globalized world. The "border crossing pedagogy" would also be relevant as the educator will assist learners to reconstruct and demystify the tension in SS. Hence H Giroux maintains that: ${ }^{88}$

Border pedagogy extends the meaning and importance of demystification as a central pedagogical task... students must be offered opportunities to read texts that both affirm and interrogate the complexity of their own histories... to engage and develop a counter discourse to the established boundaries of knowledge... In this perspective, culture is not viewed as monolithic or unchanging, but as a shifting sphere of multiple and heterogeneous borders where different histories... intermingle... There are no unified subjects here, only students whose multilayered and often contradictory voices and experiences intermingle with the weight of particular histories that will fit easily into the master narrative of a monolithic culture.

It is promising for the solution to the tension between the official and unofficial SS because the National Curriculum as entailed in the CAPS document states that its aim is to alter the curriculum inherited by the new SA from the apartheid regime by building it to be grounded on the values that inspired the Constitution Act 108 of 1996. The values are based on the remedial of the divisions of the past and institute a society based on democratic principles, social justice and basic rights, also to improve the quality of life

85 MC Kgari-Masondo (Personal Collection) and D Mosina (Research Assistant), interview, Self-Determined, 24 September 2016.

86 MC Kgari-Masondo (Personal Collection) and D Mosina (Research Assistant), interview, Humble, No name, Mr Educated and Determined, 27 September 2016 and Interesting, 25 September 2016.

87 H Giroux, Border crossings..., p. 49.

88 H Giroux, cited in R Phillips, “Contesting the past...”, British Journal of Education Studies, 46(1), 1998, p. 49. 
of all citizens and liberate the potential of all in SA ${ }^{89}$ In relation to SS it is a call for integration of knowledges that the content of SS focuses on which is part of the decolonization debate. The skill of multiperspectivity endorsed in the teaching of History SS illustrates that CAPS contains some post-colonial discourse many SS teachers hardly ever contemplate. Nevertheless, even though CAPS does not put it explicitly how to deal with the gaps between the reflective praxis of the curriculum it promotes the principles of dealing with such tensions. As K Jenkins and K Brickley have argued about the National History Curriculum of England and Wales, similarly one can claim that the SS official curriculum in essence 'allows' interpretation, to possibilities and multiplicity of dissimilar meanings and knowledges but they are pushed to the centre.

\section{Conclusion}

A critical reflective curriculum opens itself to transformation of its content and practice that is linked with changing times and therefore is able to adapt to the needs of its society. As RT Regelski puts it; professional praxis involves an ethical obligation of getting the right outcomes that are concrete to empower students throughout life and such results are the value-added principles. ${ }^{90}$ Thus, professionally SS as has been shown in this article, highlight that there are mischiefs relating to SS reflective praxis based on the teaching pedagogy and the name accorded to the learning area - Social Science which depicts that much work needs to be done in terms of research in the field. A question thus arises: Does SS as the study of society embrace knowledges embraced by communities on which it focuses? This means that it has to embrace the reflective praxis in line with the name of the subject.

SS is dominated with western knowledge and other epistemologies such as indigenous ones are pushed to the periphery. As noted by SJ Thornton that the curriculum of SS is more of the western knowledge and implementation of western skills. ${ }^{91}$ This implies that the SS received needs to be reworked to ensure that it deals with mischiefs embedded in it - by allowing Geography and History as SS subjects to reflect in a balanced manner in both the physical and human world of the society it serves. Since CAPS purports to ensure that it promotes human rights, inclusivity, environmental and social justice through content and context chosen for the syllabus it is thus pivotal that SS

89 Department of Basic Education, Republic of SA, National Curriculum Statement..., p. i.

90 RT Regelski, “On 'methodolatry'...”, Philosophy of Music Education Review, 10(2), 2017, p. 117.

91 SJ Thornton, "Geography in American History course", Phi Delta Kappan, 88(7), 2007, pp. 535-538. 
embraces inclusivity of analysis of the communities in an integrated fashion. ${ }^{22}$ It is envisaged that their insertion will assist in meeting the objectives of teaching SS; those of helping citizens to engage in collaboration towards the common good. ${ }^{93}$ This suggests that the value embedded in SS of instilling harmonious societal engagement and understanding dynamism can be realised by ensuring integration of SS which can be a catalyst towards the current venture in academia of decolonisation of the curriculum. This vision envisaged in this article has an impact on textbook writing, teaching and learning pedagogy, curriculum construction and positioning of the subject SS within its discipline and modus operandi that entails integration as its embedded vision. Thus, it is a stringent call for the revisiting, revising and the rewriting of the SS curriculum received in SA. Even though there is considerable work to do I believe that the proposals are already valuable to researchers, policy makers and teachers.

92 Department of Basic Education, Republic of SA, National Curriculum Statement ..., p. 5.

93 KC Barton, \& LS Levstik. Teaching History for the common good (New York and London, Routledge, 2004), p. 7. 